\title{
Synthesis of superconducting $\mathrm{Nb}_{3} \mathrm{Sn}$ coatings on $\mathrm{Nb}$ substrates
}

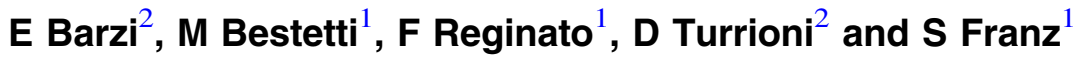 \\ ${ }^{1}$ Politecnico di Milano, Department of Chemistry, Materials and Chemical Engineering 'Giulio Natta', Via \\ Mancinelli, I-7-20131 Milano, Italy \\ ${ }^{2}$ Fermi National Accelerator Laboratory, Pine and Kirk Rds.-Batavia 60510, IL, USA \\ E-mail: barzi@fnal.gov
}

Received 23 June 2015, revised 28 September 2015

Accepted for publication 15 October 2015

Published 1 December 2015

\begin{abstract}
In the present work the electrochemical and thermal syntheses of superconducting $\mathrm{Nb}_{3} \mathrm{Sn}$ films are investigated. The $\mathrm{Nb}_{3} \mathrm{Sn}$ phase is obtained by electrodeposition of $\mathrm{Sn}$ layers and $\mathrm{Cu}$ intermediate layers onto $\mathrm{Nb}$ substrates followed by high temperature diffusion in inert atmosphere. Electrodeposition was performed from aqueous solutions at current densities in the $20-50 \mathrm{~mA} \mathrm{~cm}^{-2}$ range and at temperatures between $40{ }^{\circ} \mathrm{C}$ and $50{ }^{\circ} \mathrm{C}$. Subsequent thermal treatments were realized to obtain the $\mathrm{Nb}_{3} \mathrm{Sn}$ superconductive phase. Glow discharge optical emission spectrometry demonstrated that after thermal treatment interdiffusion of $\mathrm{Nb}$ and $\mathrm{Sn}$ occurred across a thickness of about $13 \mu \mathrm{m}$. Scanning electron microscopy allowed accurately measuring the thickness of the $\mathrm{Nb}_{3} \mathrm{Sn}$ phase, whose average for the various types of film samples was between 5.7 and $8.0 \mu \mathrm{m}$. X-ray diffraction patterns confirmed the presence of a cubic $\mathrm{Nb}_{3} \mathrm{Sn}$ phase (A15 structure) having (210) preferred orientation. The maximum obtained $T_{\mathrm{c}}$ was $17.68 \mathrm{~K}$ and the $B_{\mathrm{c} 20}$ ranged between 22.5 and $23.8 \mathrm{~T}$. With the procedure described in the present paper, coating complex shapes cost-effectively becomes possible, which is typical of electrochemical techniques. Furthermore, this approach can be implemented in classical wire processes such as 'jelly roll' or 'rod in tube', or directly used for producing superconducting surfaces. The potential of this method for superconducting radiofrequency structures is also outlined.
\end{abstract}

Keywords: $\mathrm{Nb}_{3} \mathrm{Sn}$ thin films, electrochemical deposition, x-ray diffraction

(Some figures may appear in colour only in the online journal)

\section{Introduction}

The intermetallic compound $\mathrm{Nb}_{3} \mathrm{Sn}$ is a type II superconductor having a close to stoichiometric composition (from 18 to 25 at\% Sn) and A15 crystal structure. It has a critical temperature $T_{c 0}$ of up to $18.1 \mathrm{~K}$ and an upper critical magnetic field $B_{c 20}$ of up to $30 \mathrm{~T}$ [1]. As a comparison, the ductile alloy NbTi has a $T_{c 0}$ of $9.8 \mathrm{~K}$ and a $B_{c 20}$ of $14.5 \mathrm{~T}$, which make $\mathrm{NbTi}$ adequate only up to operational magnetic fields of 8-9 T. Due to $\mathrm{Nb}_{3}$ Sn's stronger superconducting properties, it enables magnets above $10 \mathrm{~T}$, which for instance is a larger field than any existing in present NbTi particle accelerators. $\mathrm{Nb}$, which is used for radio frequency (SRF) structures, has a $T_{c 0}$ of $9.2 \mathrm{~K}$ and $B_{c 20}$ smaller than $1 \mathrm{~T}$. The development of a successful and industrially scalable $\mathrm{Nb}_{3} \mathrm{Sn}$ coating would improve an SRF cavity quality factor $Q_{0}$ by at least tenfold at $4.5 \mathrm{~K}$ thanks to the higher $T_{c}$.

Some of the challenges are that $\mathrm{Nb}_{3} \mathrm{Sn}$ requires hightemperature processing, which makes it brittle, and its critical current is strain sensitive, i.e. high strain on the sample may reduce or totally destroy its superconductivity. In recent decades, several manufacturing processes have been developed to produce superconductive $\mathrm{Nb}_{3} \mathrm{Sn}$ wires [2-5], and Fermi National Accelerator Laboratory (Fermilab, US) has used these wires to develop superconducting cables and 
perform $\mathrm{Nb}_{3} \mathrm{Sn}$ research for high field accelerator magnets $[6,7]$. During this research, in 2001 a phenomenological model that aimed at improving flux pinning properties in $\mathrm{Nb}_{3} \mathrm{Sn}$ wires for high field magnets was published [8]. The results presented here on electrochemical and thermal syntheses of superconductive $\mathrm{Nb}_{3} \mathrm{Sn}$ films on $\mathrm{Nb}$ substrates originated from trying to experimentally verify this model in collaboration with a group of experts from Politecnico di Milano (POLIMI) [9]. As electrodeposition is scalable to any 3D surface, this technique could allow us, for the first time, to use superconductors as surface coatings as opposed to bulk, wires and cables.

In addition, while coating $\mathrm{Nb}$ with $\mathrm{Nb}_{3} \mathrm{Sn}$, our team was able to produce direct deposits of molecular $\mathrm{Nb}_{3} \mathrm{Sn}$ on a $\mathrm{Cu}$ substrate. This would be the first time that $\mathrm{Nb}_{3} \mathrm{Sn}$ is reproducibly formed directly in molecular form and at much lower temperatures $\left(100{ }^{\circ} \mathrm{C}-130{ }^{\circ} \mathrm{C}\right)$ than in any other state-of-theart method, which is by solid diffusion at very high temperature $\left(650^{\circ} \mathrm{C}+\right)$. The results of this latter work were published in a separate journal [10].

The best yet demonstration of superconducting RF properties of $\mathrm{Nb}_{3} \mathrm{Sn}$ has been its growth via high temperature vapor diffusion of $\mathrm{Sn}$ onto bulk $\mathrm{Nb}$ cavity structures followed by thermal reaction aimed at forming the A-15 compound conformally inside the RF cavity. This work was started in the 1980s at the University of Wuppertal and has been replicated and further developed at Cornell University [11], and at Thomas Jefferson National Accelerator Facility (JLab) [12]. High field performance is yet less than desired. There is no precedence for forming $\mathrm{Nb}_{3} \mathrm{Sn}$ on $\mathrm{Cu}$ substrates.

$\mathrm{A} \mathrm{Nb}_{3} \mathrm{Sn}$ thin film process such as electrodeposition allows films of this material to be studied easily and to solve the materials problems that are presently limiting the maximum gradients in $\mathrm{Nb}_{3} \mathrm{Sn}$ cavities. A strong incentive is the theoretical prediction that gradients about twice as high as for niobium could be obtained. While there are other ways to produce this A15 compound, electrodeposition would be among the most inexpensive ways to mass produce SRF cavities for a long accelerator. In fact, electrodeposition techniques allow the deposition of metals and alloys on complex 3D shapes and require lower capital costs when compared to vacuum deposition techniques. Furthermore, electrochemical techniques can eliminate the problem of a low tin concentration at the niobium interface, which is a fundamental limit of the current vapor deposition techniques. Finally, electrodeposition techniques can be implemented in classical processes as 'jelly roll' or 'rod in tube' or directly used for the production of superconducting surfaces.

Only a few works are available in literature on the application of electrochemical techniques to the production of $\mathrm{Nb}_{3} \mathrm{Sn}$. In the ' 80 s some works described the manufacturing of $\mathrm{Nb}_{3} \mathrm{Sn}$ wires by electrodeposition of $\mathrm{Sn}$ onto $\mathrm{Cu}-\mathrm{Nb}$ alloys [13-16], or by electrodeposition of $\mathrm{Cu}-\mathrm{Sn}$ alloys onto $\mathrm{Nb}$ filaments [17]. No mention is made of $\mathrm{Nb}_{3} \mathrm{Sn}$ coatings. More recently, some authors proposed the synthesis of $\mathrm{Nb}_{3} \mathrm{Sn}$ coatings by electrodeposition $[18,19]$ and by galvanic displacement of $\mathrm{Nb}$ in molten salts containing $\mathrm{SnCl}_{2}$ [20]. The main disadvantages of these approaches are that they require temperatures higher than $370{ }^{\circ} \mathrm{C}$ and residual pressures no higher than 2.5 $\mathrm{Pa}$ in order to remove adsorbed moisture, gases, and residual moisture. Therefore most of the common advantages of electroplating (i.e. operation at room or near-room temperatures and atmospheric pressure) are lost. Previous studies from Koura et al [21-23] described the electrodeposition of $\mathrm{Nb}_{3} \mathrm{Sn}$ coatings from ionic liquids based on 1-butylpyridinium chloride (BPC) or on 1-ethyl-3-methylimidazolium chloride (EMIC). X-ray diffraction (XRD) analyses and resistivity tests demonstrated that a superconductive $\mathrm{Nb}_{3} \mathrm{Sn}$ phase could be obtained [24]. However, the same authors declared that the reproducibility of the process was not acceptable. More recently the same group [25] tested a Lewis basic EMIC melt producing $\mathrm{Nb}_{3} \mathrm{Sn}$ along with metallic $\mathrm{Sn}$ and $\mathrm{Cu}_{10} \mathrm{Sn}_{3}$ alloy. However, no indication of the thickness of the $\mathrm{Nb}_{3} \mathrm{Sn}$ film was given, questioning the eligibility of the approach for actual applications and for further development to the industrial scale.

In the present paper, a combination of thermal diffusion processes and electrochemical techniques is proposed to obtain thick superconductive $\mathrm{Nb}_{3} \mathrm{Sn}$ coatings onto $\mathrm{Nb}$ substrates. The approach was to electrodeposit a seed copper layer onto the $\mathrm{Nb}$ substrate, followed by a tin layer and a copper barrier layer. The electrodeposition processes were carried out using aqueous solutions working at near-room temperatures and atmospheric pressure. Samples were then heat treated and characterized. Details of the fabrication process are given in the following.

\section{Experimental setup and methods}

Electrodeposition tests were carried out on niobium foils of $1 \mathrm{~cm} \times 3 \mathrm{~cm}$ having thickness of $250 \mu \mathrm{m}$. Prior to deposition, the niobium foils were degreased in acetone and cleaned in diluted acid to reduce the presence of niobium oxides on the surface. Niobium oxides reduce the adhesion of electrodeposited metals and act as a diffusional barrier layer during the heat treatment, hindering the formation of the superconductive phase. It is therefore important to proceed with electrodeposition without delay after the thorough chemical treatment of the $\mathrm{Nb}$. The electrodeposition of tin was performed using the commercial bath Solderon ${ }^{\mathrm{TM}} \mathrm{MHS}-\mathrm{W}$ at a current density of $50 \mathrm{~mA} \mathrm{~cm}^{-2}$ and bath temperature of $50{ }^{\circ} \mathrm{C}$. Copper seed layers were electrodeposited at $30 \mathrm{~mA} \mathrm{~cm}^{-2}$ and $40{ }^{\circ} \mathrm{C}$ using a sulphate-based electrolyte whose composition is reported in table 1. Copper barrier layers were deposited from a pyrophosphate-based electrolyte whose composition is reported in table 2. The $\mathrm{pH}$ of the electrolyte was 8.5. Electrodeposition experiments were carried out at $20 \mathrm{~mA} \mathrm{~cm}^{-2}$ and $50{ }^{\circ} \mathrm{C}$. Electrolytes were prepared from analytical grade chemicals and deionized water. Electrodeposition experiments were made in a two electrodes cell, where the anode was a copper sheet and the cathode a $\mathrm{Nb}$ foil. Deposition times ranged from 1 to $25 \mathrm{~min}$

Heat treatments were performed in a computer controlled tubular furnace. The oven was equipped with three separately programmable induction resistances. Temperature 
Table 1. Composition of electrolyte used for the deposition of the copper seed layer.

\begin{tabular}{lc}
\hline Chemicals & Concentration $\left(\mathrm{g} \mathrm{l}^{-1}\right)$ \\
\hline $\mathrm{CuSO}_{4}$ & 60 \\
$\mathrm{H}_{2} \mathrm{SO}_{4}$ & 200 \\
$\mathrm{HCl}$ & 40 \\
\hline
\end{tabular}

Table 2. Composition of the electrolyte used for the deposition of the copper barrier layer.

\begin{tabular}{lc}
\hline Chemicals & Concentration $\left(\mathrm{g} \mathrm{l}^{-1}\right)$ \\
\hline $\mathrm{Cu}_{2} \mathrm{P}_{2} \mathrm{O}_{7}$ & 26 \\
$\mathrm{NaNO}_{3}$ & 5 \\
$\mathrm{Na}_{4} \mathrm{P}_{2} \mathrm{O}_{7}$ & 180 \\
\hline
\end{tabular}

Table 3. Thickness of $\mathrm{Sn}$ and $\mathrm{Cu}$ layers in $\mathrm{Nb} / \mathrm{Cu} / \mathrm{Sn} / \mathrm{Cu}$ samples.

\begin{tabular}{lcc}
\hline Sample & $\begin{array}{c}\text { Thickness of Sn } \\
\text { layer }(\mu \mathrm{m})\end{array}$ & $\begin{array}{c}\text { Thickness of } \mathrm{Cu} \text { barrier } \\
\text { layer }(\mu \mathrm{m})\end{array}$ \\
\hline Type 1 & 10 & 10 \\
Type 2 & 15 & 15 \\
Type 3 & 20 & 15 \\
\hline
\end{tabular}

was continuously monitored by two thermocouples. Heat treatments were performed in argon atmosphere. To determine the diffusional parameters, samples were observed using an optical microscope. The samples were prepared for optical microscope observation by means of classical metallurgical techniques: they were placed in an epoxy resin and accurately sliced by means of a metallographic sectioning saw. The exposed surface was grinded by means of a Buehler HandiMet ${ }^{\circledR}$ roll grinder, using sandy papers from a 240 to 600 grit. The final polishing was performed by an automatic grinding and polishing system (LECO GPX-300). Samples were observed after heat treatment using an inverted metallurgical microscope (Nikon ECLIPSE) connected to a computer with a camera control unit. The Imaging Software used for the analysis was 'NIS-Elements', which gives the possibility to apply smart filters to the image, such as different phase and grain boundary recognition. The maximum optical magnification was $500 \times$.

For superconductivity tests, a commercial magnetocryostat equipped with a variable temperature insert (VTI) was used, whose operation temperature is from 1.5 to $300 \mathrm{~K}$. For transport current measurements, an original setup that had been designed to measure the critical current dependence on magnetic field orientation for anisotropic high temperature superconductor tapes was used after the appropriate modifications. Since the $\mathrm{Nb}-\mathrm{Sn}-\mathrm{Cu}$ films after reaction cannot be soldered, the original soldered contacts used to transfer the current from the $\mathrm{Cu}$ current leads to the samples were replaced by a sample holder with pressure contacts. For the same reason, the voltage tap wires were attached to stainless steel screws that were put in contact with the sample. Using the modified setup, film samples were tested for critical current $I_{\mathrm{c}}$ in liquid He at $4.2 \mathrm{~K}$ and in magnetic fields from $0 \mathrm{~T}$ up to $14 \mathrm{~T}$. The tests were performed both in a field parallel and perpendicular to the tape, as shown in figure 1 (left). An electrical field criterion of $E_{\mathrm{c}}=1 \mu \mathrm{V} \mathrm{m}^{-1}$ was used to define the critical current. The measurement of the critical temperature $T_{\mathrm{c}}$ of the samples was performed in the VTI using a DC method with currents between 1 and $3 \mathrm{~A}$. The temperature was measured with a Lakeshore Cernox 1030, which had been calibrated down to $1.6 \mathrm{~K}$, and which was placed in contact with the film sample inside one of the copper lugs.

The crystallographic structure of the $\mathrm{Nb}-\mathrm{Sn}$ coatings was assessed by XRD using a Philips PW1830 instrument, with $\mathrm{Cu} \mathrm{K} \alpha 1$ radiation and Bragg-Brentano geometry. XRD was performed in the $2 \theta$ angular range of $10-90^{\circ}$. An approximate measure of the grain size was evaluated by calculating the crystal coherence extensions according to Scherrer equation. Glow discharge optical emission spectrometry (GDOES) depth profiling analyses were performed with a Spectruma GDA750 analyzer using argon ions for sputtering with a beam spot size of $2.5 \mathrm{~mm}$. The scanning electron microscopy (SEM) was performed on sample cross sections using a SEM - JEOL ${ }^{\circledR} 5900$ with tungsten filament, operated at $20 \mathrm{kV}$. The cross sections used for the SEM were cut longitudinally $5 \mathrm{~mm}$ away from the sample edge (figure 1, right), and half of the sample length was used in order to measure film thickness homogeneity.

\section{Results and discussion}

\section{Electrodeposition of $\mathrm{Sn}$ and Cu layers on $\mathrm{Nb}$ substrates}

Preliminary electrodeposition experiments of Sn layers were carried onto $\mathrm{Nb}$ substrates at $50 \mathrm{~mA} \mathrm{~cm}^{-2}$ and $50{ }^{\circ} \mathrm{C}$. The coating showed high roughness and scarce adhesion on the $\mathrm{Nb}$. On the other hand, the electrodeposition of $\mathrm{Sn}$ onto copper substrates resulted in a bright $\mathrm{Sn}$ coating with good adhesion. In addition, as shown in figure 2, the growth rate of the Sn film on copper substrates was about $1.25 \mu \mathrm{m} \mathrm{min}^{-1}$, i.e. higher than that onto $\mathrm{Nb}$ substrates (about $0.63 \mu \mathrm{m} \mathrm{min}^{-1}$ ). The most efficient thermal techniques for obtaining superconductive $\mathrm{Nb}_{3} \mathrm{Sn}$ wires through solid diffusion at high temperature require the presence of copper. $\mathrm{Nb}_{3} \mathrm{Sn}$ is formed by solid diffusion at high temperature $\left(650^{\circ} \mathrm{C}\right.$ or higher). In the binary $\mathrm{Nb}-\mathrm{Sn}$ system, single-phase $\mathrm{Nb}_{3} \mathrm{Sn}$ layers form only above $\sim 930{ }^{\circ} \mathrm{C}$, where the only stable phase is $\mathrm{Nb}_{3} \mathrm{Sn}$. At temperatures below $845^{\circ} \mathrm{C}$, the two non-superconducting phases $\mathrm{NbSn}_{2}$ and $\mathrm{Nb}_{6} \mathrm{Sn}_{5}$ are also stable and all three phases will grow at the interface, with $\mathrm{NbSn}_{2}$ most rapidly formed and $\mathrm{Nb}_{3} \mathrm{Sn}$ being the slowest [26]. However, in the ternary system $(\mathrm{Nb}-\mathrm{Cu}-\mathrm{Sn})$ the only relevant stable phase is $\mathrm{Nb}_{3} \mathrm{Sn}$ even at lower temperatures [1]. The diffusion path from the $\mathrm{Cu}-\mathrm{Sn}$ solid solution to the $\mathrm{Nb}-\mathrm{Sn}$ solid solution passes through only the A15 phase field, destabilizing the formation of the nonsuperconductive phases $\mathrm{NbSn}_{2}$ and $\mathrm{Nb}_{6} \mathrm{Sn}_{5}$. Therefore, the addition of $\mathrm{Cu}$ lowers the $\mathrm{A} 15$ formation temperature from well above $930{ }^{\circ} \mathrm{C}$ to any other that is deemed practical, 

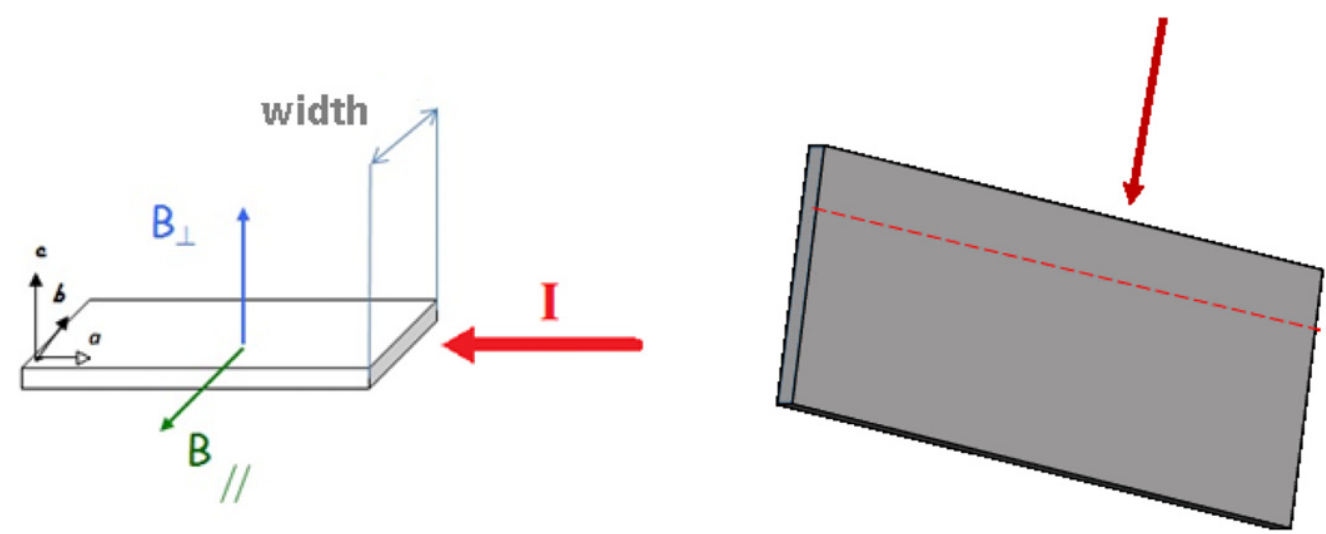

Figure 1. Parallel and perpendicular orientations used for the magnetic field in critical current measurements (left); and schematic of cross section used when performing sample SEM (right).

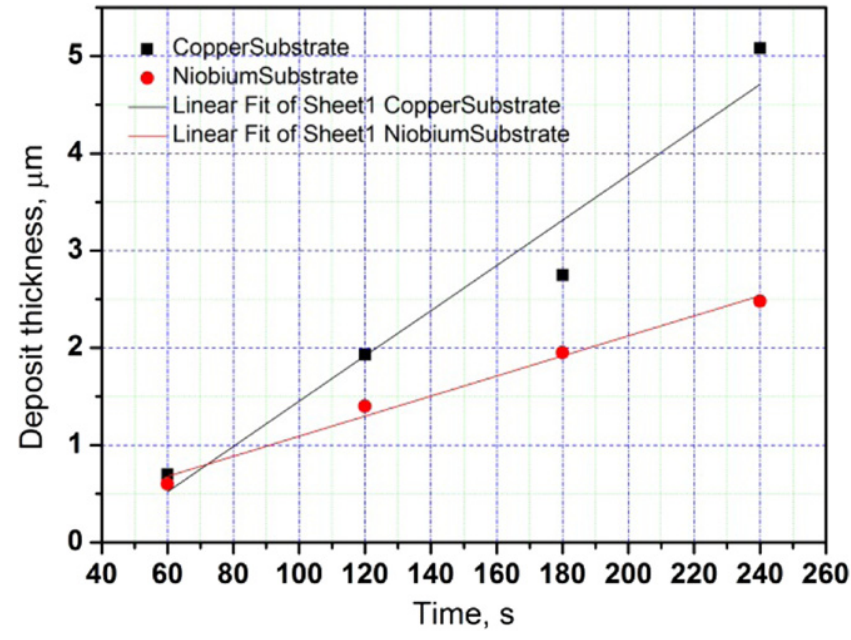

Figure 2. Thickness of Sn coatings on copper substrates (a) and on $\mathrm{Nb}$ substrates (b) as a function of deposition time.

thereby limiting grain growth and thus retaining a higher grain boundary density required for flux pinning. Although $\mathrm{Cu}$ can be detected in the A15 layers, it is generally assumed to exist only at the grain boundaries and not to appear in the A15 grains, allowing to use the binary A15 phase diagram to qualitatively interpret compositional analysis in wires. Also, to the first order, the addition of $\mathrm{Cu}$ does not dramatically change the superconducting behavior of wires as compared to binary systems [27]. Therefore, the conclusion was made that a copper seed layer should be deposited onto the $\mathrm{Nb}$ substrates prior to the deposition of the Sn film.

Electrodeposition of copper on $\mathrm{Nb}$ was carried out from a sulphate-based electrolyte at $30 \mathrm{~mA} \mathrm{~cm}^{-2}$ and $40{ }^{\circ} \mathrm{C}$. The resulting coating was bright and adherent (figure 3(a)). As expected, the subsequent deposition of tin on the copper seed layer resulted in a coating adherent to the substrate (figure 3(b)). The XRD pattern (figure 3(c)) revealed that the Sn coating onto the copper substrate had a crystalline tetragonal structure with a slight (211) preferred orientation.

Thermal treatments on $\mathrm{Nb} / \mathrm{Cu} / \mathrm{Sn}$ samples (see the following section) evidenced that $\mathrm{Sn}$ coalesces into small lumps during heating, producing a severe inhomogeneous tin distribution. This issue was addressed by changing sample design. A copper barrier layer was deposited onto the Sn coating in order to restrain the coalescence effect and maintain the coverage of the $\mathrm{Nb}$ substrate homogeneous. The copper barrier layer was deposited from a pyrophosphatebased electrolyte at $20 \mathrm{~mA} \mathrm{~cm}^{-2}$ and $50{ }^{\circ} \mathrm{C}$. Thermal treatments for superconductivity tests were carried out on samples having the sandwiched structure represented in figure 3(d). Three types of samples were fabricated, based on the thickness of the tin and copper barrier layers. The thickness of the Sn layer ranged between 10 and $20 \mu \mathrm{m}$, and the thickness of the copper barrier layer was either 10 or $15 \mu \mathrm{m}$, as indicated in table 3.

\section{Calculation of diffusional parameters}

The diffusional parameters were determined by annealing $\mathrm{Nb} / \mathrm{Cu} / \mathrm{Sn}$ samples. In the case of $\mathrm{Nb}-\mathrm{Sn}$ systems, a parabolic growth rate was suggested in literature for the newly forming superconductive layer [26]. This behavior is derived from first Fick's law, assuming a constant concentration of the diffusing component at both the boundaries of the interlayer, and a constant concentration gradient across the interlayer:

$$
J_{i}=-D_{i} \frac{\partial C_{i}}{\partial x}
$$

where $J$ is the diffusional flux ( $\mathrm{mol} \mu \mathrm{m}^{-2} \mathrm{~s}$ ), $D$ is the diffusion coefficient $\left(\mu \mathrm{m}^{2} \mathrm{~s}^{-1}\right), C$ is the concentration $\left(\mathrm{mol} \mu \mathrm{m}^{-3}\right)$ and $x$ is the width of the concentration gradient $(\mu \mathrm{m})$. More precisely the parabolic growth can be described by the simple law:

$$
L=\sqrt[n]{2 D t}
$$

where $L$ is the thickness of the new phase created after the heat treatment $(\mu \mathrm{m}), n$ is usually considered equal to $2, D$ $\left(\mu \mathrm{m}^{2} \mathrm{~s}^{-1}\right)$ is the interdiffusion coefficient and $t$ is the duration of the heat treatment in seconds. Large deviations from the parabolic growth rate are primarily due to cracks in the layers for $n<2$, and to depletion of Sn in the matrix for $n>2$. The interdiffusion coefficient can be written in an Arrhenius form 


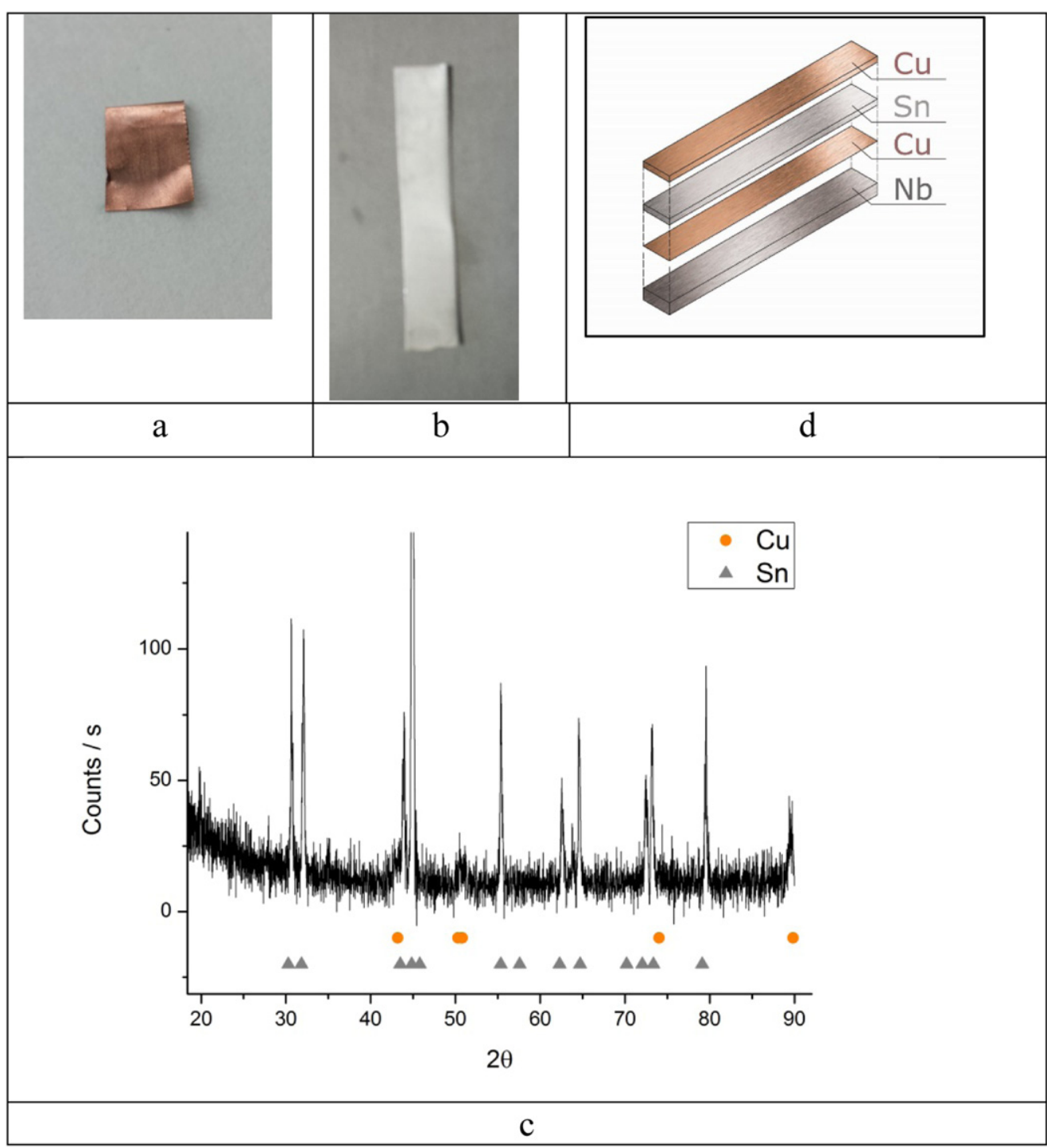

Figure 3. Copper seed layer onto $\mathrm{Nb}$ substrate (a), Sn coating onto $\mathrm{Nb} / \mathrm{Cu}$ substrates (b), XRD pattern of a $\mathrm{Nb} / \mathrm{Cu} / \mathrm{Sn}$ sample (c) and final sample design for superconductivity tests (d).

as:

$$
D=D_{0} \exp \left(-\frac{Q_{0}}{R T}\right)
$$

where $D_{0}\left(\mu \mathrm{m}^{2} \mathrm{~s}^{-1}\right)$ is the diffusion frequency, $Q_{0}\left(\mathrm{~kJ} \mathrm{~mol}^{-1}\right)$ is the activation energy for diffusion, $R$ is the gas constant $\left(\mathrm{kJ} \mathrm{K}^{-1} \mathrm{~mol}^{-1}\right.$ ) and $T(\mathrm{~K})$ is the reaction temperature. The thickness of the newly formed phase was sampled in ten different locations and the average value was calculated (table 4).

At temperatures below the melting point of tin $\left(232^{\circ} \mathrm{C}\right)$, diffusion was negligible. At higher temperatures, diffusion becomes significant, but the tin layer coalesced forming small domains and leaving the niobium substrate partly uncovered. The thickness of the newly formed $\mathrm{Nb}-\mathrm{Sn}$ phase could be evaluated in the areas where good coverage was maintained. However, in view of further analysis and practical applications, the samples design was later changed (see following section).
In figure 4 , the experimental thickness of the $\mathrm{Nb}-\mathrm{Sn}$ phase is reported as a function of the duration of the heat treatment, and it is compared to curves calculated based on data reported in literature. In table 5 the calculated values for $D_{0}$ and $Q_{0}$ are reported and compared with others found in literature. The experimental activation energy for diffusion $Q_{0}$ was about $202 \mathrm{~kJ} \mathrm{~mol}^{-1}$. Values reported in literature are between 221 and $404 \mathrm{~kJ} \mathrm{~mol}^{-1}$. High values of $Q_{0}$ are not desired because it means lower diffusion rates and higher duration of heat treatments, with excessive grain growth and loss of the superconductive properties. As shown in table 5, the value of $Q_{0}$ determined in the present work is lower than that measured for $\mathrm{Nb}$ surrounded by a bronze matrix [28, 29].

\section{Heat treatment of $\mathrm{Nb} / \mathrm{Cu} / \mathrm{Sn} / \mathrm{Cu}$ samples}

$\mathrm{Nb} / \mathrm{Cu} / \mathrm{Sn} / \mathrm{Cu}$ samples were processed following the thermal profile shown in figure 5 . The initial step was carried out at a temperature of $214 \pm 2{ }^{\circ} \mathrm{C}$ for $72 \mathrm{~h}$, slightly lower than 
Table 4. Temperature and duration of thermal treatments, thickness of the resulting $\mathrm{Nb}-\mathrm{Sn}$ phase and corresponding standard deviation.

\begin{tabular}{lccc}
\hline Sample & $\begin{array}{c}\text { Temperature } \\
\left({ }^{\circ} \mathrm{C}\right)\end{array}$ & Duration $(\mathrm{h})$ & $\begin{array}{c}\text { Thickness of Nb-Sn } \\
\text { phase }(\mu \mathrm{m})\end{array}$ \\
\hline 1 & 220 & 20 & No diffusion \\
2 & 400 & 20 & No diffusion \\
3 & 800 & 40 & $4.2 \pm 0.36$ \\
4 & 800 & 20 & $3.9 \pm 0.44$ \\
5 & 950 & 20 & $12.7 \pm 0.48$ \\
\hline
\end{tabular}

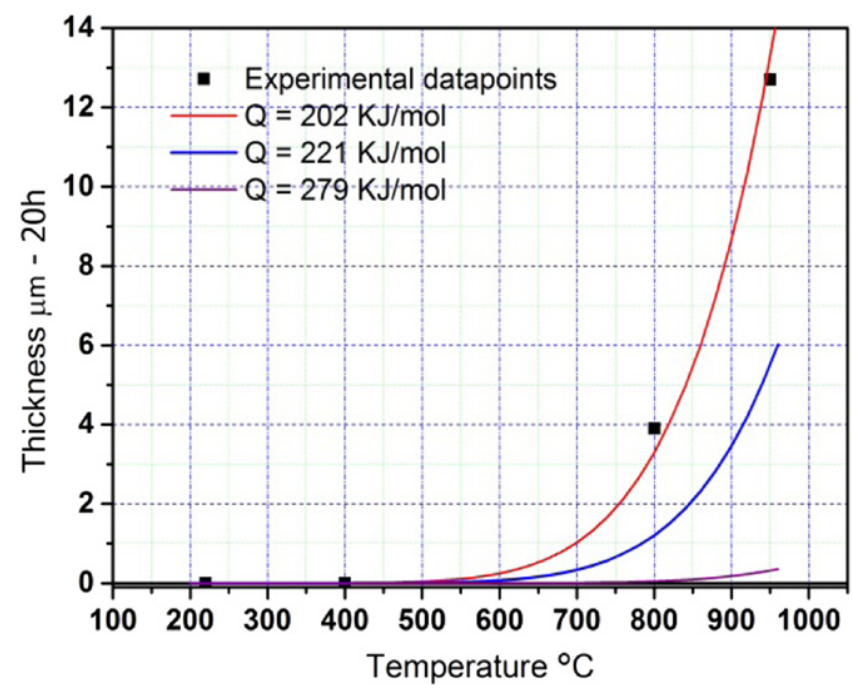

Figure 4. Thickness of the $\mathrm{Nb}-\mathrm{Sn}$ phase as a function of the duration of the heat treatment, compared to data reported in literature.

Table 5. Experimental $D_{0}$ and $Q_{0}$, and values of $Q_{0}$ reported in literature.

\begin{tabular}{lcc}
\hline Sample design before TT & $D_{0}\left(\mu \mathrm{m}^{2} \mathrm{~s}^{-1}\right)$ & $Q_{0}\left(\mathrm{~kJ} \mathrm{~mol}^{-1}\right)$ \\
\hline $\mathrm{Sn} / \mathrm{Nb}[27]$ & - & 221 \\
$\mathrm{CuSn} 7 / \mathrm{Nb}[26]$ & - & 404 \\
$\mathrm{CuSn8} / \mathrm{Nb}[26]$ & - & 279 \\
This work & $2 \times 10^{9}$ & 202 \\
\hline
\end{tabular}

the Sn melting point, to allow for relaxation of the internal stresses in the metal layers and to start the diffusion between $\mathrm{Cu}$ and $\mathrm{Sn}$. According to literature, during this step a $3 \mu \mathrm{m} \eta$ phase should form [30]. The second intermediate step at $458 \pm 2{ }^{\circ} \mathrm{C}$ for $10 \mathrm{~h}$ was done to allow the formation of a liquid tin phase and start the interdiffusion with niobium and copper. This intermediate step was necessary in order to avoid the Kirkendall effect and consequently a severe degradation of the materials properties. Furthermore, higher temperatures would induce higher $\mathrm{Sn}$ pressures onto the $\mathrm{Cu}$ barrier layer, with a possible damage of the same and consequent Sn leakage. According to literature, after ten hours at $\sim 450{ }^{\circ} \mathrm{C}$, a bronze $\varepsilon$ phase forms on the surface, and an $\eta$ phase develops underneath. Finally, the temperature was increased to $699 \pm 1{ }^{\circ} \mathrm{C}$ for a duration of $24 \mathrm{~h}$ to form the $\mathrm{Nb}_{3} \mathrm{Sn}$ superconducting phase. After the heat treatment, small tin islands were observed only on the surface of type 1 samples,

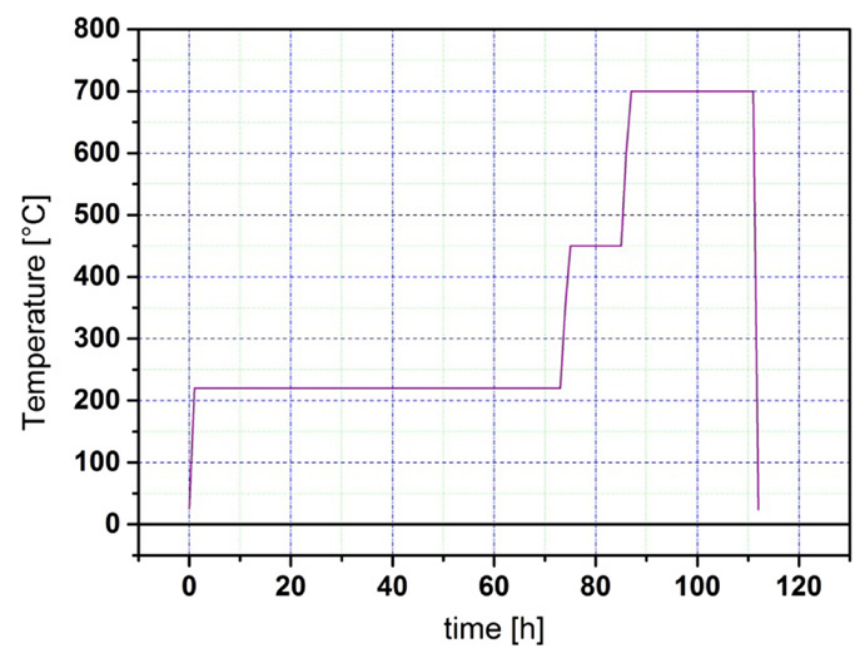

Figure 5. Average temperature as monitored by two thermocouples located with the $\mathrm{Nb} / \mathrm{Cu} / \mathrm{Sn} / \mathrm{Cu}$ samples during reaction versus time profile.

presumably because of the lower thickness of the copper barrier layer.

Table 6 shows the parameters of the $\mathrm{Nb}-\mathrm{Sn}-\mathrm{Cu}$ film samples that were tested after reaction. In table 6 , thickness and width values were measured with micrometer and caliber respectively in five locations along the samples. The average length of the samples was $37.41 \pm 0.51 \mathrm{~mm}$.

\section{Characterization of $\mathrm{Nb} / \mathrm{Cu} / \mathrm{Sn} / \mathrm{Cu}$ samples}

$\mathrm{Nb} / \mathrm{Cu} / \mathrm{Sn} / \mathrm{Cu}$ samples after thermal treatment were characterized by means of GDOES, XRD and electrical tests. By means of GDOES analysis, the region where $\mathrm{Sn}$ and $\mathrm{Nb}$ are superimposed was defined and, in some cases, the possible position and thickness of the $\mathrm{Nb}_{3} \mathrm{Sn}$ phase was inferred. It must be noted that the in the present work the relative intensities of the GDOES signal do not give indication on the relative amount of the elements. To verify the thickness estimate obtained in the GDOES analysis, SEM was performed on longitudinal cross sections of the samples. Film composition was also assessed by EDX analysis.

According to the experimental diffusional parameters, the expected thickness of the $\mathrm{Nb}-\mathrm{Sn}$ alloy after thermal treatment was about $3.5 \mu \mathrm{m}$. In figure 6(a) the qualitative composition profile of a type 1 sample consisting of a $\mathrm{Nb} / \mathrm{Cu} / \mathrm{Sn}(10 \mu \mathrm{m}) /$ $\mathrm{Cu}(10 \mu \mathrm{m})$ multilayered structure is shown. The thickness of the $\mathrm{Nb}_{3} \mathrm{Sn}$ phase was estimated at about $5 \mu \mathrm{m}$, located at a depth of about $10 \mu \mathrm{m}$ from the surface. The SEM that was performed on a longitudinal cross section of the sample showed a maximum $\mathrm{Nb}_{3} \mathrm{Sn}$ film thickness of $6.7 \mu \mathrm{m}$. The XRD pattern (figure 6(b)) revealed the presence of a crystalline cubic $\mathrm{Nb}_{3} \mathrm{Sn}$ phase (A15 structure). Other phases were also detected: $\mathrm{NbSn}_{2}, \beta \mathrm{Sn}, \varepsilon \mathrm{Cu}_{3} \mathrm{Sn}\left(2 \theta=43.65^{\circ}\right), \mathrm{NbO}$ and $\mathrm{NbO}_{2}\left(36.98^{\circ}\right.$ and $\left.74.84^{\circ}\right)$.

Figure 7 (left) shows the DC measurement of critical temperature $T_{\mathrm{c}}$ for a type 1 sample. For this sample type, a region of slow and nearly linear rise of the resistance can be observed at the onset of normal conductivity. This effect is 


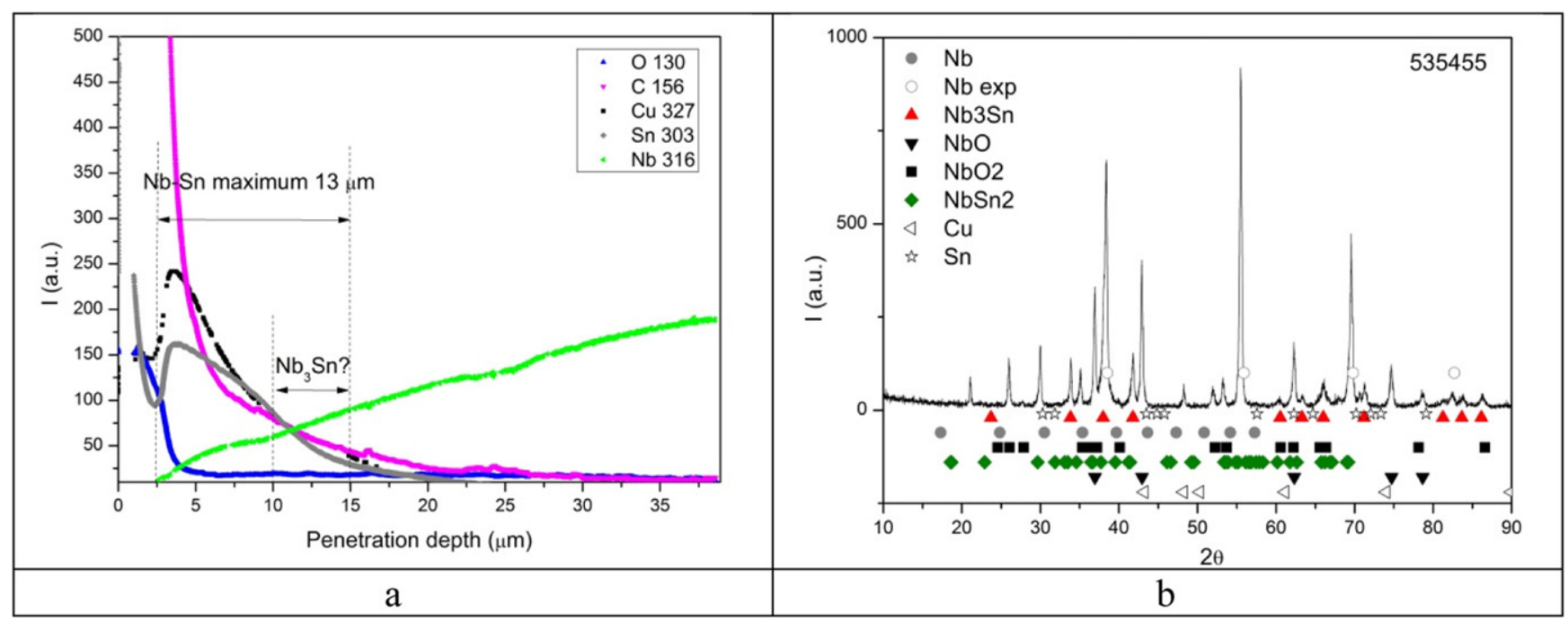

Figure 6. XRD pattern (a) and GDOES analysis (b) of sample consisting of $\mathrm{Nb} / \mathrm{Sn}(10 \mu \mathrm{m}) / \mathrm{Cu}(10 \mu \mathrm{m})$ after thermal treatment (type 1 sample).

reproducible as it was found also on the second type 1 sample, which had small $\mathrm{Sn}$ islands on its surface. The $T_{\mathrm{c}}$ value that was obtained using the definition shown in the plot was $17.438 \mathrm{~K}$. Using as definition the mid-point of the temperature range encompassing the whole transition, the $T_{\mathrm{c}}$ value was $16.65 \mathrm{~K}$

Figure 7 (right) shows the critical current $I_{\mathrm{c}}$ measured at $4.2 \mathrm{~K}$ as a function of magnetic field $B$ in both parallel and perpendicular orientations (right) for the type $1 \mathrm{Nb}-\mathrm{Sn}$ film sample without $\mathrm{Sn}$ islands on the surface. A fit [31] was performed on this set of $I_{\mathrm{c}}$ data by using the measured $T_{\mathrm{c}}$ value as a fixed parameter, and without introducing any assumptions on the strain status $\varepsilon$ of the conductor, which is not accurately known. The upper critical magnetic field at zero temperature, $B_{\mathrm{c} 20}(\varepsilon)$, was obtained as free parameters in the fitting: The results for $B_{\mathrm{c} 20}(\varepsilon)$ varied between 23.8 and $23.5 \mathrm{~T}$ for $T_{\mathrm{c}}$ values between $16.65 \mathrm{~K}$ and $17.438 \mathrm{~K}$ respectively.

In figure 8(a) the GDOES analysis of a type 2 sample consisting of a Nb/Cu/Sn$(15 \mu \mathrm{m}) / \mathrm{Cu}(15 \mu \mathrm{m})$ multilayered structure after thermal treatment is shown. The composition gradient did not allow to infer the thickness nor the position of the $\mathrm{Nb}_{3} \mathrm{Sn}$ phase. However, the SEM that was performed on a longitudinal cross section of the sample showed an average $\mathrm{Nb}_{3} \mathrm{Sn}$ film thickness of $8.0 \pm 0.5 \mu \mathrm{m}$ (figure 10 , left). The XRD pattern (figure 8(b)) shows the reflection of a crystalline cubic $\mathrm{Nb}_{3} \mathrm{Sn}$ phase (A15 structure). Other reflections can be attributed to $\mathrm{NbSn}_{2}, \beta \mathrm{Sn}, \mathrm{Cu}-\mathrm{Sn}$ phases, $\mathrm{NbO}$ and $\mathrm{NbO}_{2}$.

Figure 9 (left) shows the DC measurement of critical temperature $T_{\mathrm{c}}$ for a type 2 sample. For this sample type, the transition region is narrower and the rise of the resistance at the onset of normal conductivity is sharper than in type 1 samples. The $T_{\mathrm{c}}$ value that was obtained using the definition shown in the plot was $17.454 \mathrm{~K}$. Using as definition the midpoint of the temperature range encompassing the whole transition, the $T_{\mathrm{c}}$ value was $17.066 \mathrm{~K}$.
Figure 9 (right) shows the critical current $I_{\mathrm{c}}$ measured at $4.2 \mathrm{~K}$ as a function of magnetic field $B$ in both parallel and perpendicular orientations (right) for a type $2 \mathrm{Nb}-\mathrm{Sn}$ film. The same fit method was used as in the case of the type 1 sample. The results for $B_{\mathrm{c} 20}(\varepsilon)$ varied between $23.4 \mathrm{~T}$ and $23.3 \mathrm{~T}$ for $T_{\mathrm{c}}$ values between $17.066 \mathrm{~K}$ and $17.454 \mathrm{~K}$ respectively.

In figure 11(a) the GDOES analysis and corresponding XRD pattern of a type 3 sample $(\mathrm{Nb} / \mathrm{Cu} / \mathrm{Sn}(20 \mu \mathrm{m}) / \mathrm{Cu}$ $(15 \mu \mathrm{m}))$ after thermal treatment are reported. Based on the GDOES analysis, the thickness of the $\mathrm{Nb}_{3} \mathrm{Sn}$ phase was estimated at about $5 \mu \mathrm{m}$. The SEM that was performed on a longitudinal cross section of the sample showed an average $\mathrm{Nb}_{3} \mathrm{Sn}$ film thickness of $5.7 \pm 0.5 \mu \mathrm{m}$ (figure 10, right). According to the XRD pattern (figure $11(\mathrm{~b})$ ), $\mathrm{a} \mathrm{Nb}_{3}$ Sn phase having cubic structure with a strong (210) preferred orientation is present. Compared to the other XRD patterns, the signal to noise ratio increased, probably due to mechanical cleaning of the sample surface before XRD analysis. $\mathrm{NbSn}_{2}$ $\left(2 \theta=18.71^{\circ}\right.$ and $\left.58.19^{\circ}\right), \mathrm{NbO}_{2}\left(26.14^{\circ}-35.28^{\circ}-52.13^{\circ}\right)$, $\mathrm{Cu}_{6} \mathrm{Sn}_{5}\left(68.27^{\circ}\right), \beta \mathrm{Sn}\left(30.24^{\circ}\right), \mathrm{Cu}\left(30.24^{\circ}\right)$ were also detected. In all cases, the GDOES analysis revealed that the region where $\mathrm{Sn}$ and $\mathrm{Nb}$ elements are superimposed was about $13 \mu \mathrm{m}$ thick and confirmed the presence of oxygen in the outer $3 \mu \mathrm{m}$.

Figure 12 (left) shows the DC measurement of critical temperature $T_{\mathrm{c}}$ for a type 3 sample. For this sample type, the transition behavior is similar to that in the type 2 sample. The $T_{\mathrm{c}}$ value that was obtained using the definition shown in the plot was $17.684 \mathrm{~K}$. Using as definition the mid-point of the temperature range encompassing the whole transition, the $T_{\mathrm{c}}$ value was $17.128 \mathrm{~K}$.

Figure 12 (right) shows the critical current $I_{\mathrm{c}}$ measured at $4.2 \mathrm{~K}$ as a function of magnetic field $B$ in both parallel and perpendicular orientations (right) for two type $3 \mathrm{Nb}-\mathrm{Sn}$ films. The same fit method was used as in the case of the type 1 sample. The results for $B_{\mathrm{c} 20}(\varepsilon)$ varied between $22.6 \mathrm{~T}$ and 
Table 6. Film sample parameters after reaction.

\begin{tabular}{lccccccl}
\hline & & \multicolumn{2}{c}{ Thickness, mm } & & \multicolumn{2}{c}{ Width, mm } & \multirow{2}{*}{ Notes } \\
\cline { 3 - 4 } Sample ID & Sample set & Average & Standard dev. & Average & Standard dev. & \\
\hline Type 1 & 535455 & 0.274 & 0.026 & & 8.762 & 0.230 & \\
Type 1 & 535455 & & & & & Small Sn islands \\
Type 2 & 565758 & 0.359 & 0.029 & & 7.548 & 0.164 & Broken \\
Type 2 & 565758 & 0.336 & 0.012 & & 7.994 & 0.225 & \\
Type 3, 1st & 596061 & 0.367 & 0.023 & & 7.480 & 0.173 & \\
Type 3, 2nd & 596061 & 0.342 & 0.007 & & 8.900 & 0.137 & \\
\hline
\end{tabular}
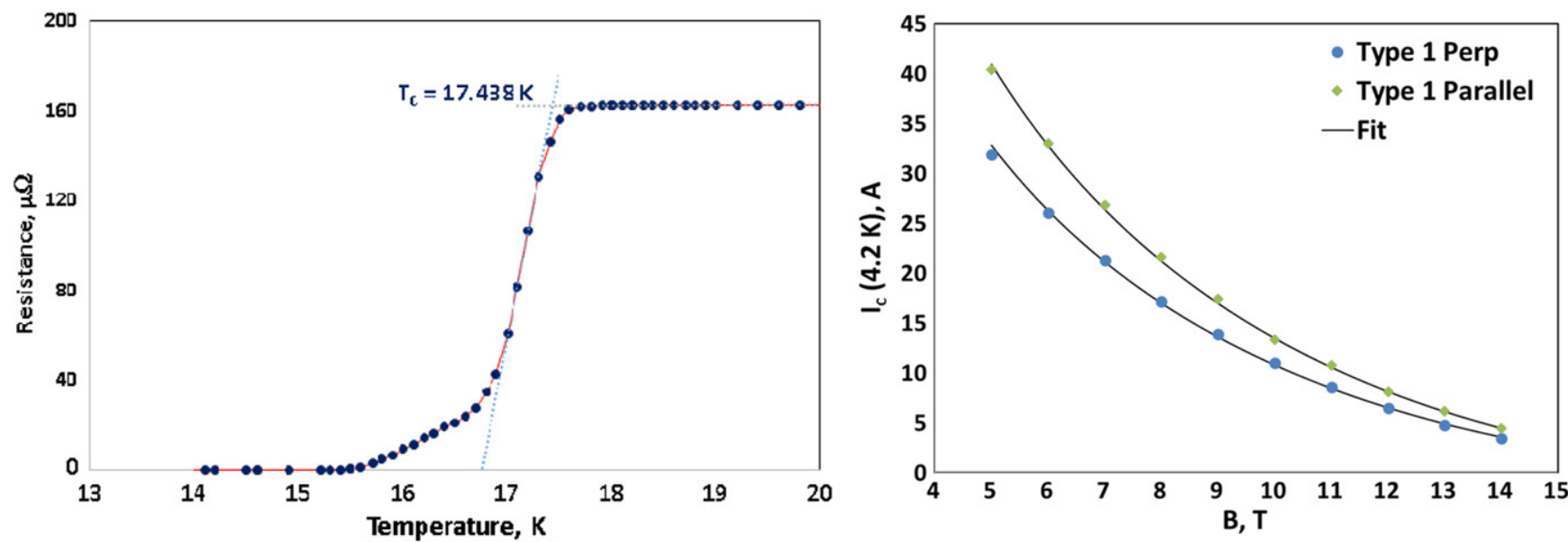

Figure 7. Dc measurement of critical temperature $T_{\mathrm{c}}$ (left), and critical current $I_{\mathrm{c}}$ at $4.2 \mathrm{~K}$ as a function of magnetic field $B$ in both parallel and perpendicular orientations (right) for a type $1 \mathrm{Nb}-\mathrm{Sn}$ film sample.

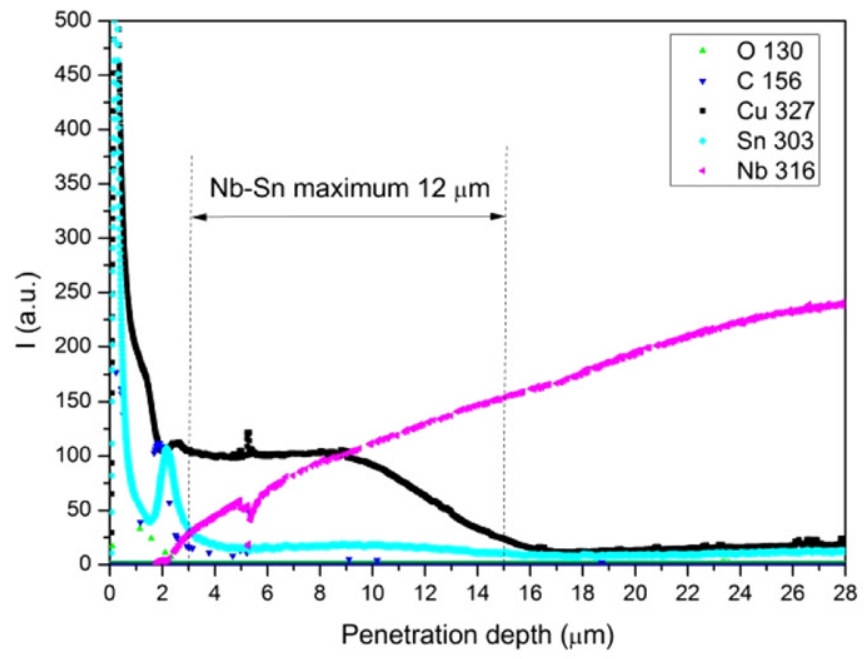

a

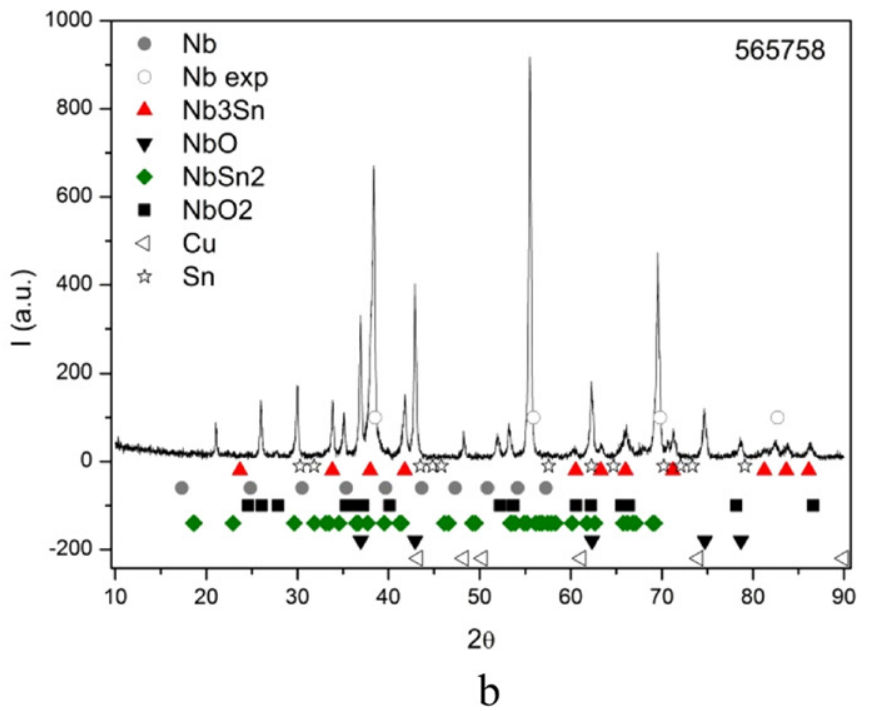

b

Figure 8. XRD pattern (a) and GDOES analysis (b) of a $\mathrm{Nb} / \mathrm{Sn}(15 \mu \mathrm{m}) / \mathrm{Cu}(15 \mu \mathrm{m})$ sample after thermal treatment (type 2 sample).

$22.5 \mathrm{~T}$ for $T_{\mathrm{c}}$ values between $17.128 \mathrm{~K}$ and $17.684 \mathrm{~K}$ respectively.

Elemental EDX measurements were performed in a number of points over the longitudinal cross-sections prepared for the SEM. The elemental composition of the $\mathrm{Nb}_{3} \mathrm{Sn}$ films typically showed $76 \mathrm{at} \% \mathrm{Nb}$ and 24 at $\% \mathrm{Sn}$. As also seen in the GDOES analyses, a $\mathrm{Cu}-\mathrm{Sn}$ layer of similar size forms above the $\mathrm{Nb}_{3} \mathrm{Sn}$ film. This outer bronze phase was measured as 74 at\% $\mathrm{Cu}$ and 26 at \% $\mathrm{Sn}$, which is consistent with the $\mathrm{Cu}-\mathrm{Sn} \varepsilon$ phase. The white spots in figure 10 are associated to $\mathrm{Sn}$ and $\mathrm{Sn}$ rich $\mathrm{Cu}-\mathrm{Sn}$ phases.

The crystallite size $\tau$ of samples after thermal treatment was estimated by the Scherrer's equation [32]:

$$
\tau=K \lambda / \beta 2 \cos \theta,
$$



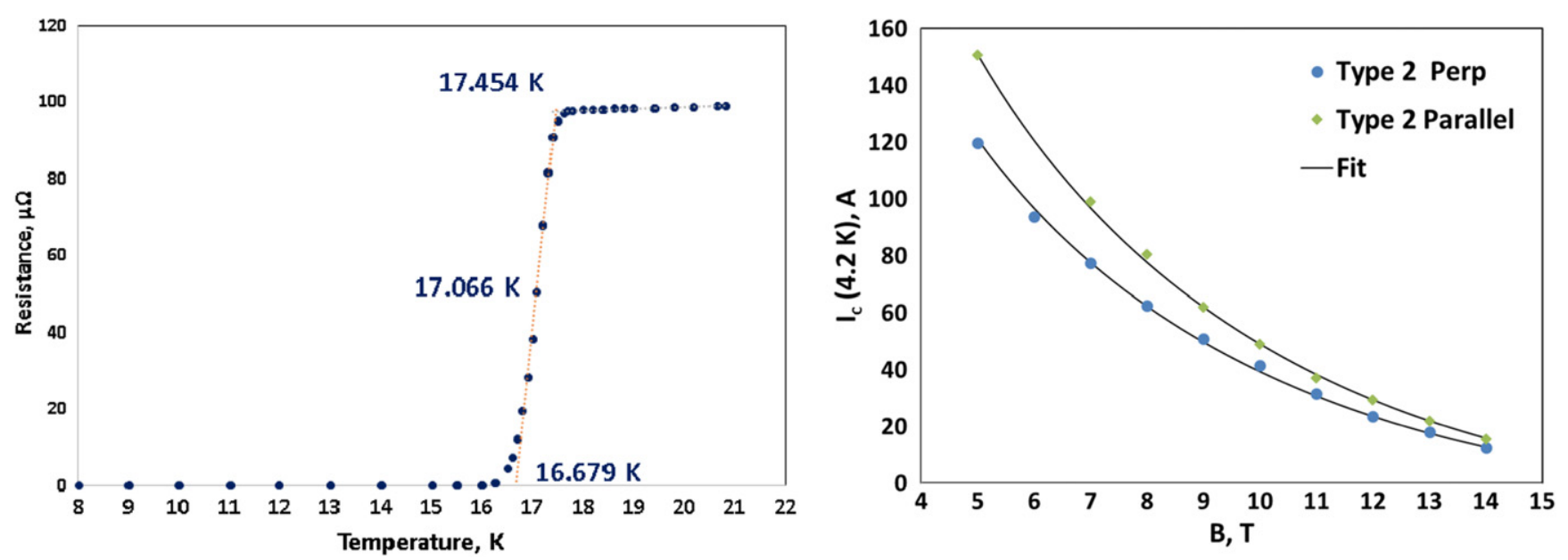

Figure 9. Dc measurement of critical temperature $T_{\mathrm{c}}$ (left), and critical current $I_{\mathrm{c}}$ at $4.2 \mathrm{~K}$ as a function of magnetic field $B$ in both parallel and perpendicular orientations (right) for a type $2 \mathrm{Nb}-\mathrm{Sn}$ film sample.

where $K$ is the shape factor (taken as 0.94 for cubic crystals), $\lambda$ is the $\mathrm{x}$-ray wavelength ( 1.54 for $\mathrm{Cu} \mathrm{K \alpha}$ radiation), $\beta$ is the line broadening (full width at half maximum, FWHM), and $\theta$ is the Bragg angle. The average crystallite size of the electrodeposited $\mathrm{Nb}-\mathrm{Sn}$ alloys was about $27 \mathrm{~nm}$ for type 1 , $24 \mathrm{~nm}$ for type 2 and $32 \mathrm{~nm}$ for the type 3 sample. Grain sizes in $\mathrm{Nb}_{3} \mathrm{Sn}$ films obtained by e-beam co-evaporation onto $\mathrm{Si}$ substrates [33] were between 20 and $100 \mathrm{~nm}$.

Table 7 summarizes the results of this analysis. With this very first attempt at producing $\mathrm{Nb}_{3} \mathrm{Sn}$ films by electrodeposition, reasonably good superconducting properties were already obtained. The maximum obtained $T_{\mathrm{c}}$ was $17.68 \mathrm{~K}$ and the $B_{\mathrm{c} 20}$ ranged between 22.5 and $23.8 \mathrm{~T}$.

Whereas samples made with the thinnest Sn layers had crystallites without any preferential orientation, the sample type with the thickest $\mathrm{Sn}$ layer showed a strong preferred (210) orientation. This is consistent with the larger anisotropy of the latter's transport current, shown in table 7 as $I_{\mathrm{c} \|} / I_{\mathrm{c} \perp}$. This phenomenon will have to be better understood in light of the importance of grain orientation in flux pinning.

\section{Conclusions}

The results of the synthesis of $\mathrm{Nb}_{3} \mathrm{Sn}$ thin films onto $\mathrm{Nb}$ substrates were presented herein. Superconductive coatings were obtained by combining thermal treatments and the electrochemical technique for thin film deposition. Samples were fabricated by electrodeposition of a $\mathrm{Cu}$ seed layer onto the $\mathrm{Nb}$ substrate, followed by deposition of a Sn layer $(10-20 \mu \mathrm{m})$ and a $\mathrm{Cu}$ barrier layer $(10-15 \mu \mathrm{m})$. Subsequent thermal treatments were carried out to form the $\mathrm{Nb}_{3} \mathrm{Sn}$ phase. The copper seed layer improved adhesion of tin onto the substrate, while the copper barrier layer limited tin coalescence during thermal treatments. Both layers were expected to favor the formation of the $\mathrm{Nb}_{3} \mathrm{Sn}$ phase.

Diffusional parameters were determined, indicating a thickness of the $\mathrm{Nb}-\mathrm{Sn}$ phase after thermal treatment of about
$3.5 \mu \mathrm{m}$. GDOES analysis revealed that the region where Sn and $\mathrm{Nb}$ are superimposed was about $13 \mu \mathrm{m}$ thick. In some cases it was possible to infer that the thickness of the $\mathrm{Nb}_{3} \mathrm{Sn}$ phase was about $5 \mu \mathrm{m}$, at about $10 \mu \mathrm{m}$ from the sample surface. The XRD patterns revealed the presence of both $\mathrm{Nb}_{3} \mathrm{Sn}+\mathrm{NbSn}_{2}$ crystalline phases and of $\mathrm{Cu}-\mathrm{Sn}$ phases. The SEM and EDX that were performed on longitudinal cross sections of the samples confirmed more accurately these findings, with the average thickness of the different types of film samples between 5.7 and $8.0 \mu \mathrm{m}$. Electrical tests showed a very good superconductive behavior with a majority of the samples having $T_{\mathrm{c}}$ higher than $17 \mathrm{~K}$ and $B_{\mathrm{c} 20}$ larger than $23 \mathrm{~T}$.

The next step of this research, subject to appropriate funding, will be using this technique for possible applications, such as high performance superconducting magnetic shields for accelerator magnets, MRI, MAGLEV and other applications and/or high performance superconducting RF cavities for particle accelerators and light sources. For application of this method to RF cavities, appropriate mechanical and/or chemical polishing techniques will have to be used to remove the superficial bronze layer $\sim 10 \mu \mathrm{m}$ thick, and expose the superconducting $\mathrm{Nb}_{3} \mathrm{Sn}$ film as RF working surface. The relatively large thickness of the $\mathrm{Nb}_{3} \mathrm{Sn}$ layer produced will offer sufficient margin for the use of electropolishing, which can be controlled with $1 \mu \mathrm{m}$ accuracy.

The development of a successful and industrially scalable $\mathrm{Nb} / \mathrm{Nb}_{3} \mathrm{Sn}$ coating would improve an SRF cavity $Q_{0}$ factor by at least tenfold at $4.5 \mathrm{~K}$ thanks to the higher $T_{\mathrm{c}}$. This would considerably reduce the cryogenic costs of high-frequency machines, since operating near the boiling point in liquid Helium rather than in superfluid Helium requires less powerful cryomodules. If in addition to a larger $Q_{0}$ factor, $\mathrm{Nb}_{3} \mathrm{Sn}$ coated cavities with larger gradients than for $\mathrm{Nb}$ were produced as expected, based on the higher superheating critical magnetic field $H_{\text {sh }}$ of $\mathrm{Nb}_{3} \mathrm{Sn}$, this would also reduce the length and therefore the costs of linear accelerators such as an international linear collider (ILC). 

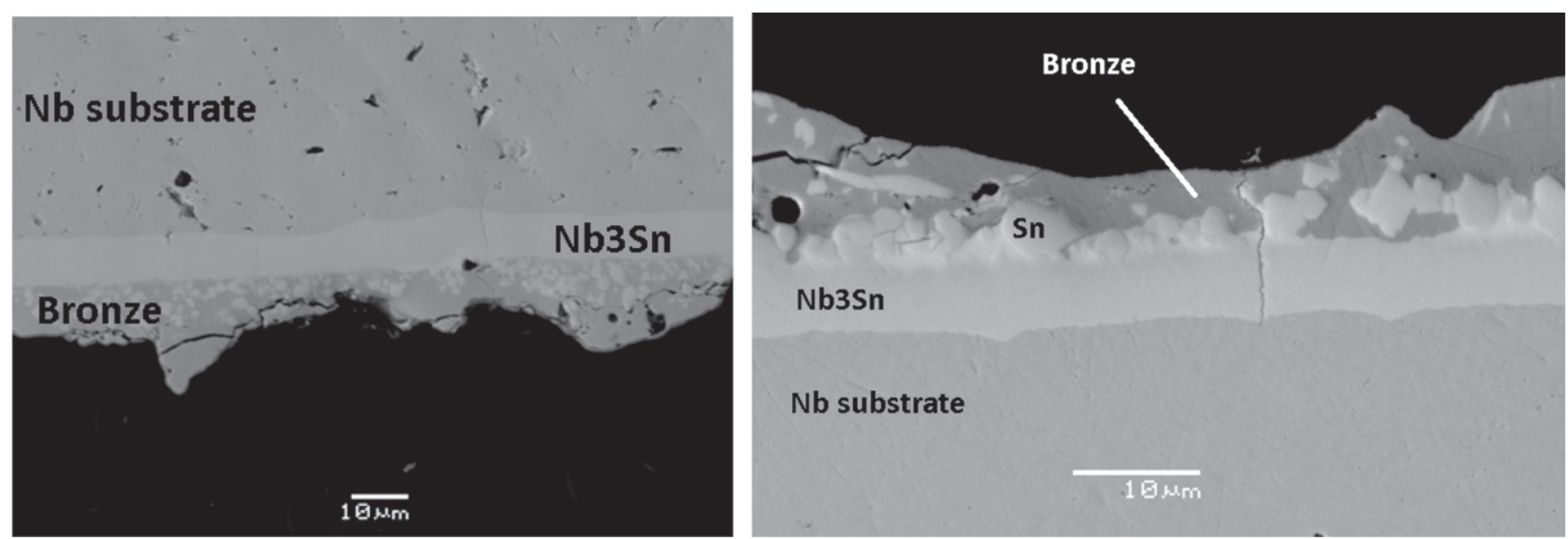

Figure 10. SEM cross-sectional pictures of type 2 sample (left) and of type 3 sample (right). The average $\mathrm{Nb}_{3} \mathrm{Sn}$ film thickness in the type 2 sample was $8.0 \pm 0.5 \mu \mathrm{m}$. The average $\mathrm{Nb}_{3} \mathrm{Sn}$ film thickness in the type 3 sample was $5.7 \pm 0.5 \mu \mathrm{m}$.



a

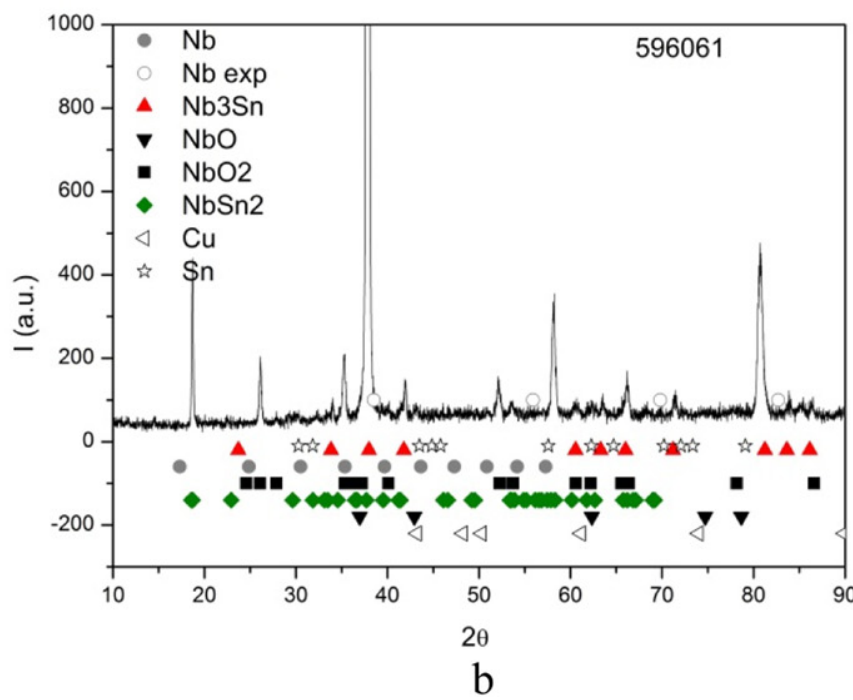

Figure 11. GDOES analysis (a) and XRD pattern (b) of a Nb/Sn(20 $\mu \mathrm{m}) / \mathrm{Cu}(15 \mu \mathrm{m})$ sample after thermal treatment (type 3 sample).
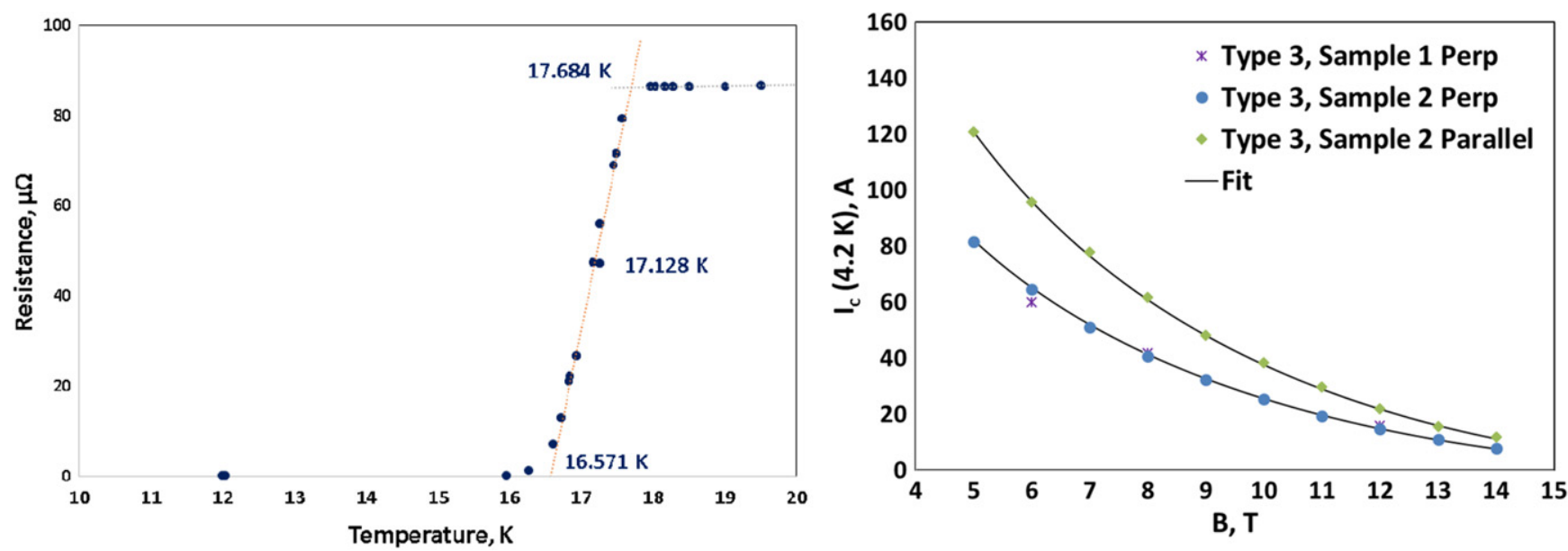

Figure 12. Dc measurement of critical temperature $T_{\mathrm{c}}$ (left), and critical current $I_{\mathrm{c}}$ at $4.2 \mathrm{~K}$ as a function of magnetic field $B$ in both parallel and perpendicular orientations (right) for type $3 \mathrm{Nb}-\mathrm{Sn}$ film samples. 
Table 7. Calculated crystallite size, preferred orientation (P.O.), and superconducting properties of $\mathrm{Nb}_{3} \mathrm{Sn}$ thin films.

\begin{tabular}{lccccccc}
\hline Sample ID & Crystallite size $(\mathrm{nm})$ & P. O. & $I_{\mathrm{c} \perp}(4.2 \mathrm{~K}, 12 \mathrm{~T})(\mathrm{A})$ & $I_{\mathrm{cll}}(4.2 \mathrm{~K}, 12 \mathrm{~T})(\mathrm{A})$ & $I_{\mathrm{cll}} / I_{\mathrm{c} \perp}$ & $T_{\mathrm{c}}(\mathrm{K})$ & $B_{\mathrm{c} 20}(\mathrm{~T})$ \\
\hline Type 1 & 27 & None & 6.5 & 8 & 1.23 & $16.65-17.44$ & $23.5-23.8$ \\
Type 2 & 24 & None & 24 & 29 & 1.21 & $17.07-17.45$ & $23.3-23.4$ \\
Type 3 & 31 & 210 & 15 & 22 & 1.47 & $17.13-17.68$ & $22.5-22.6$ \\
\hline
\end{tabular}

\section{Acknowledgments}

E Barzi thanks Pei Li for performing the SEM cross-sectional analyses, and Charles Reece, Grigory Eremeev, Anne Marie Valente, Rongli Geng, Thomas Proslier, Peter Ostroumov, EJ Taylor, Akira Yamamoto, Hayano Hitoshi, and Enzo Palmieri for useful discussions and insights. This work was partially supported by Fermi Research Alliance, LLC, under contract No. DE-AC02-07CH11359 with the U.S. Department of Energy.

\section{Reference}

[1] Foner S and Schwartz B B (ed) 1981 Superconductor Material Science (New York: Plenum)

[2] Gregory E 1989 Practical Fabrication Method for $\mathrm{Nb}_{3} \mathrm{Sn}$ vol 77 (Piscataway, NJ: IEEE) p 8

[3] Lindenhovius J H, Hornsveld E M, den Ouden A, Wessel W A J and ten Kate H H J 1999 Progress in the development of $\mathrm{Nb}_{3} \mathrm{Sn}$ conductors based on the 'powder in tube' method with finer filaments IEEE Trans. Appl. Supercond. 91451

[4] Gregory E, Gulko E, Pyon T and Goodrich L F 1996 Properties of internal Tin $\mathrm{Nb}_{3} \mathrm{Sn}$ strand for the international thermonuclear experimental Reactor Adv. Cryog. Eng. 42 1319-28

[5] Field M B, Zhang Y, Miao H, Gerace M and Parrell J A 2014 Optimizing $\mathrm{Nb}_{3} \mathrm{Sn}$ conductors for high field applications IEEE Trans. Appl. Supercond. 246001105

[6] Zlobin A V et al 2007 Development of $\mathrm{Nb}_{3} \mathrm{Sn}$ accelerator magnet technology at Fermilab Proc. PAC2007 (Albuquerque, NM, June 2007)

[7] Zlobin A V et al 2015 Quench performance of the first twinaperture $11 \mathrm{~T}$ dipole for lhc upgrades Proc. IPAC2015 (Richmond, VA, June 2015)

[8] McDonald J and Barzi E 2001 A Model for $\mathrm{J}_{\mathrm{c}}$ in Granular A-15 Superconductors IEEE Trans. Appl. Supercond. 113884

[9] Reginato F 2014 Electrochemical synthesis of Nb-Sn coatings for high field accelerator magnets Laurea Thesis Politecnico di Milano

[10] Franz S, Barzi E, Turrioni D, Glionna L and Bestetti M 2015 Electrochemical synthesis of $\mathrm{Nb}_{3} \mathrm{Sn}$ coatings on $\mathrm{Cu}$ substrates Mater. Lett. 161 613-5

[11] Liepe M and Posen S 2014 Advances in development of $\mathrm{Nb}_{3} \mathrm{Sn}$ superconducting radio-frequency cavities Phys. Rev. ST Accel. Beams 15112001

[12] Eremeev G, Reece C E, Kelley M J, Pudasaini U and Tuggle J R 2015 Development of a $\mathrm{Nb}_{3} \mathrm{Sn}$ cavity vapor diffusion deposition system, Thomas Jefferson National Accelerator Facility Proc. SRF2013 (Whistler, Canada)

[13] Verhoeven J D, Sue J J, Finnemore D K, Gibson E D and Ostenson J E 1980 The morphology and grain size of $\mathrm{Nb} \mathrm{Sn}$ filaments in in situ prepared multifilamentary $\mathrm{Nb}_{3} \mathrm{Sn}-\mathrm{Cu}$ composite wire J. Mater. Sci. 15 1907-14
[14] Spencer C R, Erik A, Gregory E, Marancik W and Rosen C Z 1980 Production of $\mathrm{Nb}_{3} \mathrm{Sn}$ by the in-situ process IEEE Trans. Magn. MAG-17 257-60

[15] Spencer C, Adam E, Gregory E, Hong S, Koop D and Reverri G 1981 Development and fabrication of 12 tesla $\mathrm{Nb}_{3} \mathrm{Sn}$ superconductors IEEE Trans. Magn. 17 1006-9

[16] LeHuyc H, Germaind L, Robergea R and Fonerb S 1984 Laboratory scale electroplating and processing of long lengths of in situ $\mathrm{Cu}_{3} \mathrm{Sn}$ superconductors Cryogenics 24 $171-4$

[17] Cogan S, Kwon S, Klein J and Rose R 1983 Fabrication of large diameter external-diffusion processed $\mathrm{Nb}_{3} \mathrm{Sn}$ composites IEEE Trans. Magn. 19 1139-42

[18] Kolosov V N and Matychenko E S 1998 Evaluation of High Frequency Superconductivity of Niobium Coatings Prepared by Electrodeposition Process in Molten Salts, in Refractory Metals in Molten Salts (Dordrecht: Kluwer) pp 231-8

[19] Kolosov V N and Shevyrev A A 2004 Effect of heat treatment on the structure and properties of superconducting $\mathrm{Nb}$ and $\mathrm{Nb}_{3} \mathrm{Sn}$ electrodeposits Inorg. Mater. 40 235-40

Kolosov V N and Shevyrev A A 2004 Neorg. Mater. 40 286-91 (transl.)

[20] Kolosov V N and Novichkov V Y 2003 Zero-current deposition of superconducting $\mathrm{Nb}_{3} \mathrm{Sn}$ coatings from molten salts Inorg. Mater. 39 485-91

Kolosov V N and Novichkov V Y 2003 Neorg. Mater. 39 583-90 (transl.)

[21] Ito H, Koura N and Ling G 1995 Electrodeposition of Nb-Sn alloy from ambient temperature molten salt electrolytes Hyoumen Gijutsu 46 1162-6

[22] Ito H, Koura N and Ling G 1997 Electrodeposition of Nb-Sn alloy from ambient temperature molten salt electrolytes by pulse electrolysis Hyoumen Gijutsu 48 454-9

[23] Koura N, Umebayashi T, Idemoto Y and Ling G 1999 Electrodeposition of $\mathrm{Nb}-\mathrm{Sn}$ alloy from $\mathrm{SnCl}_{2}-\mathrm{NbCl}_{5}-\mathrm{EMIC}$ ambient temperature molten salts Electrochemistry 67689

[24] Koura N, Shibano K, Matsumoto F, Matsuzawa H, Katou T, Idemoto $\mathrm{Y}$ and LING G 2001 Electrodeposition of $\mathrm{Nb}_{3} \mathrm{Sn}$ alloy superconductor from $\mathrm{NbCl}_{5}-\mathrm{SnCl}_{2}$-EMIC room temperature molten salt Hyoumen Gijutsu 52 645-6

[25] Koichi Ui S H, Takeuchi K, Ling G and Koura N 2009 Electrodeposition of $\mathrm{Nb}_{3} \mathrm{Sn}$ alloy film from lewis basic $\mathrm{SnCl}_{2}-\mathrm{NbCl}_{5}$-EMIC melt Electrochemistry 77 798-800

[26] Charlesworth J P, MacPhail I and Madsen P E 1970 Experimental work on the niobium-tin constitution diagram and related studies J. Mater. Sci. 5 580-603

[27] Godeke A 2005 Performance boundaries in $\mathrm{Nb}_{3} \mathrm{Sn}$ superconductors $P h D$ Thesis University of Twente

[28] Paul V V A and Laurila T 2010 Microstructure, diffusion and growth mechanism of $\mathrm{Nb}_{3} \mathrm{Sn}$ superconductor by bronze technique Superconductor (Rijeka: InTech) ch 3

[29] Santra S and Aloke P 2013 Effect of Ti concentration on the growth of $\mathrm{Nb}_{3} \mathrm{Sn}$ between solid $\mathrm{Nb}$ (Ti) and liquid $\mathrm{Sn}$ J. Electron. Mater. 42 2716-22

[30] Mattafirri S 2002 Kinetics of phase growth during the $\mathrm{Cu}-\mathrm{Sn}$ diffusion process and the $\mathrm{Nb}_{3} \mathrm{Sn}$ formation. Optimization of superconducting properties Laurea Thesis University of Pisa

[31] Summers L T, Guinan M W, Miller J R and Hahn P A 1991 A model for the prediction of $\mathrm{Nb}_{3} \mathrm{Sn}$ critical current as a 
function of field, temperature, strain and radiation damage IEEE Trans. Magn. 27 2041-4

[32] Cullity B D 1978 Elements of X-ray Diffraction 2nd edn (Reading, MA: Addison-Wesley)
[33] Dietderich D R, Kelman M, Litty J R and Scanlan R M 1998 High critical current densities in $\mathrm{Nb}_{3} \mathrm{Sn}$ films with engineered microstructures-artificial pinning microstructures Adv. Cryog. Eng. 44B 951 